\title{
Knowledge and Attitudes of Physicians Towards Evidence Based Medicine in Ilam, Iran
}

\author{
Milad Rashidbeygi ${ }^{1}$, Kourosh Sayehmiri ${ }^{2,3, *}$ \\ ${ }^{1}$ Medical Student, Student Research Committee, Ilam University of Medical Sciences, Ilam, IR Iran \\ 2 Psychosocial Injuries Research Center, Ilam University of Medical Sciences, Ilam, IR Iran \\ 3 Psychosocial Injuries Research Center, Ilam University of Medical Sciences, Ilam, IR Iran \\ ${ }^{*}$ Corresponding author: Kourosh Sayehmiri, Psychosocial Injuries Research Center, Ilam University of Medical Sciences, Ilam, IR Iran. Tel: +98-9183410782, E-mail: Sayehmiri@razi.
} tums.ac.ir.

Received: July 10, 2012; Revised: January 10, 2013; Accepted: Jun 11, 2013

\begin{abstract}
Background: Evidence based medicine (EBM) is very important in the process of decision making, diagnosis and treatment of patients. For years, medical schools have developed instructions for EBM to determine the attitude and knowledge of physicians towards EBM and their related educational needs.

Materials and Methods: This study was a questionnaire study among physicians. One hundred twenty physicians were selected using stratified random sampling in Ilam. A main outcome measure was attitudes and knowledge of physicians toward EBM, ability to access and interpret evidence, and best method of moving from opinion based to EBM.

Results: Of the 120 questionnaires we have sent, 94 (78.3\%) were answered.56.6\% were using the internet to answer their patients questions and $23.8 \%$ used the internet to obtain clinical evidence. Mean and standard deviation (SD) of knowledge and attitude scores were $24 \% \pm 23 \%$ and $72 \% \pm 10 \%$, respectively. Pearson correlation shows a significant relation between knowledge of physicians and years of graduation $(r=$ $-0.37, P=0.00)$. There was a significant difference between mean of knowledge score of general practitioners, specialist and subspecialist $(\mathrm{P}=0.026)$.

Conclusions: Knowledge and attitude of young physicians were more based on EBM compare to old physicians. A significant difference in knowledge mean score of physician shows that the EBM is still new in Iran, the future physician's critical need to learn EBM and necessity of entering EMB at all medical levels.

Keywords: Attitude; Knowledge; Evidence Based Medicine; Physician
\end{abstract}

\section{Background}

Evidence based medicine (EBM) means correct and wise use of optimal available evidence in the process of clinical decision making for patient care. EBM is very important for an optimal diagnosis and treatment of patients. In recent years, medical schools have developed educational instruction for EBM (1). EBM combines the superlative available evidence from clinical research and clinical evidence to achieve the best outcome (2-4). With lack of awareness of relevant research, substantial part of clinical practice in health relies on practitioners' personal experience, resulting in large variation in practice between health care workers $(5,6)$. Physicians are being encouraged to apply EBM to improve their clinical care worldwide(7). EBM offers a systematic and structured approach of medical education (8). It sensitizes physicians for necessity of updating advances in their practicing field ( 9 , 10) so it helps physicians during the process of decision making for an optimal treatment. Only few Iranian phy- sicians integrate EBM into their everyday practice; we conducted surveys among physician to determine their attitudes and knowledge about EBM.

\section{Objectives}

Only few Iranian physicians integrate EBM into their everyday practice; we conducted surveys among physician to determine their attitudes and knowledge about EBM.

\section{Materials and Methods}

\subsection{Study Design and Sample}

This study was a survay among physicians. In December 2010, after approval of University Ethics Committee we sent questionnaire forms to 120 physicians in Ilam, a city in the western part of Iran. The survey represents $60 \%$ of 200 Ilam physicians obtained from a national database, which stratified random sampling, were used for choosing physician. We define strata as: General practitioners

Copyright @ 2013, Iranian Red Crescent Medical Journal; Licensee KowsarKowsar Ltd. This is an Open Access article distributed under the terms of the Creative Commons Attribution License (http://creativecommons.org/licenses/by/3.0), which permits unrestricted use, distribution, and reproduction in any medium, provided the original work is properly cited. 
(Gp), Specialist (Sp) and sub Specialist (sub Sp). Questionnaire consists of three main sections. The first section includes their personal and professional characteristics such as: age, total years of graduation, medical specialty and sub specialty, extra training in EBM, and number of hours per day spent in different clinical arenas. In the second section, attitudes towards EBM were determined using a table with questions. In the third section, two tables with questions were designed to evaluate their knowledge about the potential resource of EBM; and their understanding of technical terms (Appendix 1). Questionnaire was used knowledge Cronbach's Alpha coefficient assess reliability of questioner. It estimated 93\% and 92\% for knowledge and attitude, respectively.

\subsection{Statistical Analysis}

Results were expressed as mean \pm SD. Association between variables knowledge, attitude, age, number of hours spent in clinical arenas and years of graduation were tested using Spearman's rank correlation coefficients and Pearson correlation coefficients. KolmogrovSmirnov test was used to test the normality of continues variables. When normal distribution assumption was not met for some variables, the square root transformation was used to change continues variables into normal distribution. The attitude score was calculated with mean of defined score as follows:

We determined three options for each question, and three score to (Agree) option, two score to (No opinion) option and one score to (Disagree) option.

Factor analysis's show that the knowledge of physicians toward EBM consists of two main compartments:

1-Source of EBM

2-Technical term of EBM

The knowledge score was calculated with the sum mean of defined score of two-compartment as follows:

Four options were determined for each question of source of EBM table, and four score to (Used to help in clinical decision making) options, three score to (Read) option, two score to (A ware but not used) option and one score to (Unaware) option. We determined four options for each question of Technical term in EBM table, and four score to (Understand and could Explain to oth- ers) option, three score to (Some understanding) option, two score to (Don't understand but would like to) option and one score to (It would not be helpful for me to understand) option. To compare knowledge and attitude of physician toward EBM according to sex and physician grade, two ways ANOVA was used. Statistical analyses were done using R software. P-value less than 0.05 were considered significant.

\section{Results}

Of the 120 questionnaires, we received 94 questionnaires (78.3\%). Table1 shows the demographic features of responders. Only $12 \%$ of physicians passed certain EBM workshop. $56.6 \%$ have used the internet to answer the questions about their patients, $23.8 \%$ have used it as first priority reference to obtain clinical evidence and $61.4 \%$ have used Medline to find clinical evidence. Only $38.5 \%$ of respondents had access to internet at their department, while 3.6\% had access at their local library and $57.9 \%$ at their home.

Table 1. Demographic Characteristics of Physicians

\begin{tabular}{lll}
\hline Characteristics & Parameter & Value \\
\hline Gp & 26 & 27.7 \\
\hline Sp & 62 & 66 \\
Sub Sp & 6 & 6.4 \\
\hline Sex & & \\
Men & & $65(69.1)$ \\
\hline Women & & $29(30.9 \%)$ \\
\hline $\begin{array}{l}\text { Age } \\
\text { Number of hours per day } \\
\text { spent in clinical arenas }\end{array}$ & Mean \pm SD & $8.3 \pm 2.1$ \\
Total years of graduation & Mean \pm SD & $7 \pm 5.3$
\end{tabular}

92.6\% of physicians believed that practicing EBM improves patients' management, and $42.5 \%$ believed that doesn't barrier in the use of EBM (Table 2). Only 5.3\% of physician used Cochrane Database of Systematic Reviews (Part of Cochrane), 8.5\% used Evidence based medicine (BMJ publishing group) in order to support the process of clinical decision making (Table 3), and 33\% could explain relative Risk to other persons (Table 4).

Table 2. Physicians Attitudes Toward EBM (Values are numbers (percentages) of Subjects Who Ticket Each Response)

\begin{tabular}{llll}
\hline Subject & Agree & No opinion \\
\hline Practicing EBM improves patients' management. & $87 / 94(92.6)$ & $6 / 94(6.4)$ & Disagree \\
\hline EBM is lead to lower costs of the health system. & $78 / 94(83)$ & $15 / 94(16)$ \\
\hline Diagnosis is essential reliable information. & $86 / 94(91.5)$ & $7 / 94(7.4)$ \\
\hline EBM is essential learning for all physicians. & $69 / 94(73.4)$ & $16 / 94(17)$ & $1 / 94(1.1)$ \\
Doesn't barrier in use the EBM. & $40 / 94(42.5)$ & $26 / 94(27.7)$
\end{tabular}


Table 3. Awareness and Perceived Usefulness of Relevant Information Source (Values are Numbers (Percentages) of Subjects who Ticket Each Response)

\begin{tabular}{lllll}
\hline Publication & Unaware & $\begin{array}{l}\text { A ware but } \\
\text { not used }\end{array}$ & Read & $\begin{array}{l}\text { Used to help in clini- } \\
\text { cal decision making }\end{array}$ \\
\hline Bandolier (published in Oxford) & $76 / 93(81.7)$ & $10 / 93(10.8)$ & $5 / 93(5.3)$ & $2 / 93(2.2)$ \\
\hline EBM (BMJ publishing group) & $61 / 94(64.9)$ & $15 / 94(16)$ & $10 / 94(10.6)$ & $8 / 94(8.5)$ \\
Effective Health Care Bulletins (Universities of Leeds and York) & $71 / 92(77.2)$ & $10 / 92(10.9)$ & $8 / 92(8.7)$ & $3 / 92(3.3)$ \\
Cochrane Database of systematic Reviews (Part of Cochrane) & $75 / 94(79.8)$ & $6 / 94(6.4)$ & $8 / 94(8.5)$ & $5 / 94(5.3)$ \\
DARE & $78 / 92(84.8)$ & $11 / 92(12)$ & $3 / 92(3.3)$ & $0 / 92(0.0)$ \\
Evidence Based Purchasing (South and West R\&D) & $79 / 92(85.9)$ & $7 / 92(7.6)$ & $5 / 92(5.4)$ & $1 / 92(1.1)$ \\
\hline
\end{tabular}

\begin{tabular}{lllll}
\hline Table 4. Understanding of Technical Term used in EBM (Values are Numbers (Percentages) of Subject who Ticket Each Response) \\
\hline Term & $\begin{array}{l}\text { It would not be helpful } \\
\text { for me to understand }\end{array}$ & $\begin{array}{l}\text { Don't understand } \\
\text { but would like to }\end{array}$ & Some understanding & $\begin{array}{l}\text { Understand and could } \\
\text { Explain to others }\end{array}$ \\
\hline Relative risk & $13 / 94(13.8)$ & $23 / 94(24.5)$ & $27 / 94(28.7)$ & $31 / 94(33)$ \\
\hline Absolute risk & $12 / 94(12.8)$ & $27 / 94(28.7)$ & $34 / 94(36.2)$ & $21 / 94(22.3)$ \\
\hline Systematic review & $14 / 94(14.9)$ & $31 / 94(33)$ & $27 / 94(28.7)$ & $22 / 94(23.4)$ \\
\hline Odds ratio & $15 / 93(16.1)$ & $30 / 93(32.3)$ & $28 / 93(30.1)$ & $20 / 93(21.5)$ \\
\hline Meta-analysis & $16 / 94(17)$ & $38 / 94(40.4)$ & $21 / 94(22.3)$ & $19 / 94(20.2)$ \\
\hline Clinical effectiveness & $12 / 94(12.8)$ & $32 / 94(34)$ & $29 / 94(30.9)$ & $21 / 94(22.3)$ \\
\hline Confidence interval & $14 / 94(14.9)$ & $39 / 94(41.5)$ & $25 / 94(26.6)$ & $16 / 94(17)$ \\
Publication bias & $12 / 94(12.8)$ & $28 / 94(29.8)$ & $32 / 94(34)$ & $22 / 94(23.4)$
\end{tabular}

Mean and SD knowledge score and attitude score were $24 \% \pm 23 \%, 72 \% \pm 10 \%$ respectively. A two way ANOVA show that knowledge score of physicians female more than physicians male $(\mathrm{P}=0.01)$ (Figure 1$)$.

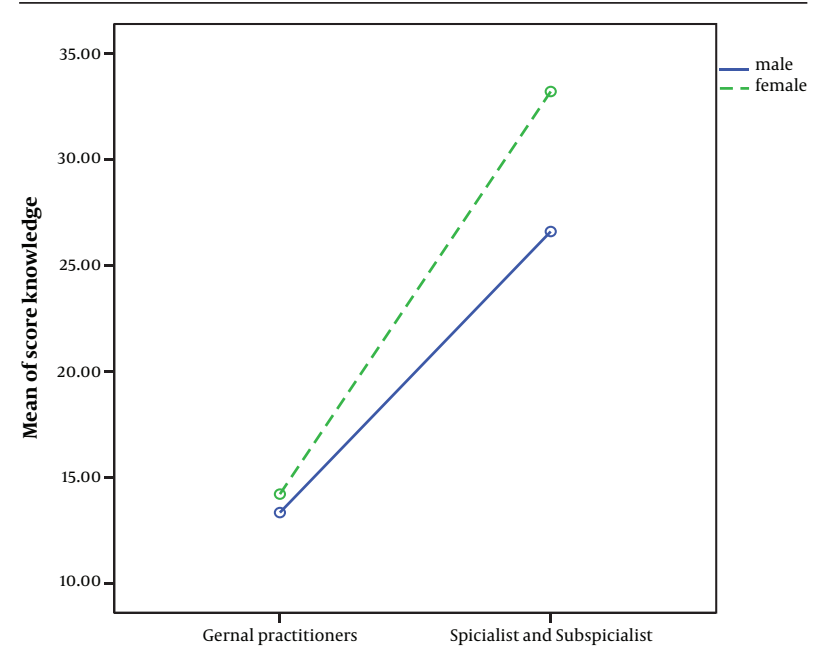

Figure 1. Comparisons Mean of Physicians Knowledge Score According to Sex

Twelve present of respondents said that "I had passed an EBM course". There was no statistical significant difference between mean score of knowledge about EBM in those who passed an EBM workshop and those who did not pass this workshop $(\mathrm{P}=0.42)$. Pearson correlation showed a significant association between knowledge of physicians and years of graduation $(r=-0.37, P=0.00)$. Negative correlation was seen between years of graduation, and the score of knowledge (Table 5).

There was a significant difference between mean of knowledge score of general practitioners, specialist and subspecialist $(\mathrm{P}=0.026)$, whereas physicians attitude toward EBM were not significantly different $(\mathrm{P}=0.73) .57 .8 \%$ of physicians have believed that partial EBM is used in Iran.

\section{Discussion}

This study was the first study to consider attitude and knowledge of graduate physicians in Iran and first study to compare EBM among general practitioner,, specialist and sub specialist physicians.

Response rates of $78.3 \%$ an important achievement as the response rate to the survey questionnaire among physicians, more than in the study of McAvoy (11). The difference between respondents' attitudes and their understanding of respondents show more positive attitude toward EBM than non-respondents (12). 57.8\% of physicians have believed that partial EBM was used in Iran, this estimation is below the previous studies, which found that more than $80 \%$ of the activity in general practice is evidence based (13). However, our finding from self-made question is limited to this study. 
Rashidbeygi $\mathrm{M}$ et al.

Table 5. Pearson Correlation Coefficient of Knowledge, Attitude, Age, Years of Graduation and Number of Hours per Spent in Clinical Arenas

\begin{tabular}{|c|c|c|c|c|c|c|}
\hline & & Knowledge & Attitude & Age & $\begin{array}{l}\text { Number of hours per } \\
\text { spent in clinical arenas }\end{array}$ & $\begin{array}{l}\text { Years of } \\
\text { graduation }\end{array}$ \\
\hline \multirow[t]{2}{*}{ Knowledge } & $\mathrm{r}$ & 1 & 0.15 & -0.13 & 0.05 & -0.36 \\
\hline & $\mathrm{P}$ & & 0.13 & 0.22 & 0.59 & 0.0 \\
\hline \multirow[t]{2}{*}{ Attitude } & $\mathrm{r}$ & & 1 & -0.05 & 0.04 & -0.11 \\
\hline & $\mathrm{P}$ & & & 0.60 & 0.65 & 0.28 \\
\hline \multirow[t]{2}{*}{ Age } & $\mathrm{r}$ & & & 1 & -0.40 & 0.65 \\
\hline & $\mathrm{P}$ & & & & 0.00 & 0.00 \\
\hline \multirow{2}{*}{$\begin{array}{l}\text { Number of hours per spent in clinical } \\
\text { arenas }\end{array}$} & $\mathrm{r}$ & & & & 1 & -0.30 \\
\hline & & & & & & 0.00 \\
\hline \multirow[t]{2}{*}{ Years of graduation } & $\mathrm{r}$ & & & & & 1 \\
\hline & $\mathrm{P}$ & & & & & \\
\hline
\end{tabular}

Used methods were criticized because based on previous study, the quality of evidence was not reviewed and non-experimental evidence was included (14). Respondents showed a low level of awareness of extracting medical journals, review update medical publications, and databases about EBM. Effort have been made to find out who uses the Cochrane Source (15) and whether gynecologists were informed of and used it (16), but there have been no such studies to compare physicians. The practice of EBM involves use of best available evidence in clinical decision making for patient care from systematic investigations (17). Much of this clinical evidence has already been identified, critically evaluated, and collected in journals and databases (18).

About medical education resources such as Cochrane and Dare, most physicians do not know this resource and only $10.6 \%$ did use it; this amount was less in the previous study (17). Our respondents showed a low knowledge of the technical terms used in EBM. Therefore, emphasis on training clinical epidemiological to physicians for use data such as Relative Risk and Odds Ratio in Clinical decision is important.

$12 \%$ of respondents said that "I had passed an EBM course". There was no statistical significant difference between mean score of EBM knowledge in those passed the workshop and those do not passed the workshop ( $\mathrm{P}=$ 0.42 ), this estimate showed EBM have been institutionalized in doctors practice.

Pearson correlation showed significant different between mean of knowledge score of general practitioners, specialist and subspecialist $(\mathrm{P}=0.026)$, which confirms EBM should be entered at all medical levels in Iran.

Significant association between knowledge of physicians and years of graduation $(r=-0.37, \mathrm{P}=0.00)$ estimated that young physicians' knowledge and attitude were more than old physician.

EBM is considered to be important for diagnosis and treatment of diseases. According to low awareness of
Ilam physicians about EBM and their interest to learn it, introduction and learning course of EBM for graduated general practitioners and specialists seems more necessary. Young physicians' knowledge and attitude is higher than older physician and a significant difference in knowledge mean score of physician exist; this shows that the EBM is still new for Iranian physicians and the future physician's critical need which should be entered at all medical levels.

\section{Acknowledgements}

We thank the Ilam physicians who took part in this survey. We thank Dr. Stefan Giebel to edit the article.

\section{Authors' Contribution}

Data collection and writing main draft of article was done by Milad Rashidbeygi, Kourosh Sayehmiri gave idea of research, design of questioner and statistical analysis. All authors read and confirm the final version of the article.

\section{Financial Disclosure}

None declared.

\section{Funding/Support}

This study was supported by a grant from the vice chancellor for research of Ilam University of Medical sciences.

\section{Appendix}

\section{Appendix 1}

\section{Part 1: Personal data}

- Age: ........

-Sex: male O female O 
-General Practice O Specialist O sub Specialist O

- Number of hours per spent in clinical arenas:.......

- Years of graduation:.......

-Do you have Internet access? Yes O No O

- In which of the following locations have access to the Internet?
Home O Clinic O Library O Other O

- If you use the Internet for clinical evidence, what sites do you use?

Medline O Specific sites O Other O

\section{Part 2: Knowledge to EBM}

\begin{tabular}{l}
\hline Table A1. Source of EBM \\
\hline Publication \\
\hline Bandolier (published in Oxford) \\
Evidence based medicine (BMJ publishing \\
group) \\
Effective Health Care Bulletins (Universities of \\
Leeds and York) \\
Cochrane Database of systematic Reviews \\
(Part of Cochrane) \\
DARE \\
Evidence Based Purchasing(South and West \\
R\&D)
\end{tabular}

\begin{tabular}{|c|c|c|c|c|}
\hline Term & $\begin{array}{l}\text { It would not be helpful for } \\
\text { me to understand }\end{array}$ & $\begin{array}{l}\text { Don't understand but } \\
\text { would like to }\end{array}$ & Some understanding & $\begin{array}{l}\text { Understand and could } \\
\text { Explain to others }\end{array}$ \\
\hline \multicolumn{5}{|l|}{ Relative risk } \\
\hline \multicolumn{5}{|l|}{ Absolute risk } \\
\hline \multicolumn{5}{|l|}{ Systematic review } \\
\hline \multicolumn{5}{|l|}{ Odds ratio } \\
\hline \multicolumn{5}{|l|}{ Meta-analysis } \\
\hline \multicolumn{5}{|l|}{ Clinical effectiveness } \\
\hline \multicolumn{5}{|l|}{ Confidence interval } \\
\hline Publication bias & & & & \\
\hline
\end{tabular}

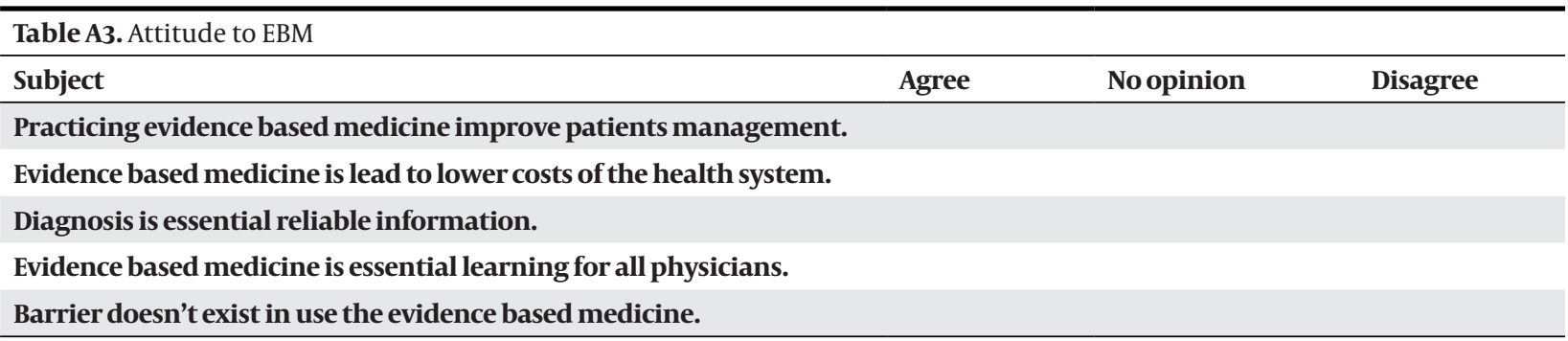

- In your opinion, how much of our current practice in Iran is based on evidence?

$$
\text { Much O Medium O Low O }
$$

\section{References}

1. Moghadami M, AMINI M. INTERNAL MEDICINE RESIDENTS'VIEWS AND UNDERSTANDING OF EVIDENCE BASED MEDICINE IN SHIRAZ MEDICAL SCHOOL. Journal of Medical Education. 2005;8(1):7-10.

2. Knottnerus JA, Dinant GJ. Medicine based evidence, a prerequi- site for evidence based medicine. BMI.1997;315(7116):1109-10.

3. Olatunbosun OA, Edouard L. The teaching of evidence-based reproductive health in developing countries. Int J Gynaecol Obstet. 1997;56(2):171-6.

4. Sackett DL, Rosenberg WM, Gray JA, Haynes RB, Richardson WS. Evidence based medicine: what it is and what it isn't. $B M J$. 1996;312(7023):71-2.

5. Grimes DA. Technology follies: The uncritical acceptance of medical innovation. JAMA. 1993;269(23):3030-3033.

6. Jacobson LD, Edwards AG, Granier SK, Butler CC. Evidence-based medicine and general practice. Br J Gen Pract. 1997;47(420):449- 
52.

7. Al-Kubaisi NJ, Al-Dahnaim LA, Salama RE. Knowledge, attitudes and practices of primary health care physicians towards evidence-based medicine in Doha, Qatar. East Mediterr Health J. 2010;16(11):1189-97.

8. MacAuley D. The integration of evidence based medicine and personal care in family practice. Ir J Med Sci.1996;165(4):289-91.

9. Evidence-based medicine - how to teach critical scientific thinking to medical undergraduates. Medical Teacher.2000;22(1):22-26.

10. Shaneyfelt T, Baum KD, Bell D, Feldstein D, Houston TK, Kaatz S, et al. Instruments for evaluating education in evidence-based practice: a systematic review. JAMA. 2006;296(9):1116-27.

11. McAvoy BR, Kaner EF. General practice postal surveys: a questionnaire too far? BMJ.1996;313(7059):732-3.

12. McColl A, Smith H, White P, Field J. General practitioner's percep- tions of the route to evidence based medicine: a questionnaire survey. BMJ.1998;316(7128):361-5.

13. Gill P, Dowell AC, Neal RD, Smith N, Heywood P, Wilson AE. Evidence based general practice: a retrospective study of interventions in one training practice. BMJ.1996;312(7034):819-21.

14. Evidence based general practice. BMJ.1996;313(7049):114 .

15. Hyde C. Who uses the Cochrane Pregnancy and Childbirth Database? BMJ.1995;310(6987):1140-1.

16. Paterson-Brown S, Wyatt JC, Fisk NM. Are clinicians interested in up to date reviews of effective care? BMJ.1993;307(6917):1464.

17. Sackett DL, Rosenberg WMC, Gray JAM, Haynes RB, Richardson WS. Evidence based medicine: what it is and what it isn't. $B M J$. 1996;312(7023):71-2.

18. Dawes MG. On the need for evidence-based general and family practice. Evidence Based Medicine. 1996;1(3):68-9. 